\title{
Masculinidades subversivas nos romances de Manuel Puig, Caio Fernando Abreu e Jaime Bayly
}

\author{
A letra, o corpo e o desejo: \\ masculinidades subversivas no \\ romance latino-americano.
}

\author{
ALÓS, Anselmo Peres. \\ Florianópolis: Mulheres, 2013. 240 p.
}

Doutor em Literatura Comparada (PPGLetras/ UFRGS) e professor da Universidade Federal de Santa Maria, Anselmo Peres Alós tem se dedicado aos estudos de gênero e das minorias marginalizadas retratadas na literatura, tendo recebido, em 2005, o prêmio Construindo a igualdade de gênero, outorgado pela Secretaria Especial de Políticas para as Mulheres, com o trabalho intitulado $A$ autoria feminina e a literatura brasileira do século XIX: novas perspectivas sobre a literatura indianista e a representação do embate colonial.' Seus estudos sobre as minorias marginalizadas retratadas na literatura estendem-se também às literaturas africanas de língua portuguesa, em especial à de Moçambique, onde foi professorvisitante no Instituto Superior de Ciências e Tecnologia de Moçambique, e à literatura latinoamericana, retratada na presente obra objeto desta resenha. ${ }^{2}$

A letra, o corpo e o desejo, publicado pela editora Mulheres em 2013, traz uma análise crítica de natureza comparatista de três romances latinoamericanos: $E l$ beso de la mujer araña, ${ }^{3}$ quarto romance do argentino Manuel Puig, publicado em 1976, Onde andará Dulce Veiga?, ${ }^{4}$ segundo romance do brasileiro Caio Fernando Abreu ${ }^{5}$, publicado em 1990, e No se lo digas a nadie, ${ }^{6}$ romance de estreia do peruano Jaime Bayly, publicado em 1994. Na análise dessas três obras, Anselmo Peres Alós dá ênfase às problemáticas da constituição performativa da identidade de gênero e ao questionamento da identidade da literatura, pensada como instituição representativa da constituição simbólica da nacionalidade.

Na apresentação do livro, a professora Sônia Maluf relembra o argumento do autor: toda leitura é política. Nessa perspectiva, em concordância com as teorias críticas contemporâneas, é válido lembrar que a primeira lição para os estudos literários é a de que a escrita e a leitura sejam pensadas como atos políticos e como formas de ação, como formas de agenciamento cruzadas por linhas de poder, centrais e hegemônicas, periféricas e marginais. ${ }^{7}$ Trata-se de um gesto interpretativo complexo abordar a homossexualidade, silenciada pelos imperativos heteronormativos, visto que uma série de crenças pressupostas como autoevidentes, regulamentadas por uma economia erótica reprodutiva, delimita as possibilidades de trocas e intercâmbios possíveis entre os corpos. Assim, a hegemonia da heterossexualidade é instaurada, tomando a lógica reprodutiva como justificativa do intercurso sexual e estabelecendo, como expressão legítima, apenas um tipo de contato e um tipo de permeabilidade corporal. ${ }^{8}$ Desta forma, a compreensão das linhas de força em confronto por ocasião da representação de identidades 
sexuais subversivas, relativas a sujeitos historicamente silenciados, especialmente com o processo de estabelecimento dos cânones literários nacionais na América Latina, é o que busca a proposta de uma poética queer de bases comparatistas. A articulação de uma epistemologia queer permite que se pense a textualidade como um lugar de encenação de uma ficção política, questionando os regimes heteronormativos do sexo e do gênero e propondo uma estética de resistência baseada tanto nos corpos e nos prazeres quanto nas políticas de representação e reinvenção das masculinidades e das feminilidades. ${ }^{9}$

El beso de la mujer araña trata do relacionamento de Valentín, um preso político da ditadura argentina, com seu companheiro de cela, Molina, acusado de corromper menores. Durante o tempo que passam na cela, Molina relata a Valentín histórias de filmes que assistiu. O romance, que, em um curto espaço de tempo, consagrouse simultaneamente como best-seller comercia e como obra de Weltliteratur, foi traduzido para mais de 15 idiomas e também traduzido "semiologicamente" para o teatro pelo próprio autor e para o cinema pelo cineasta Hector Babenco. No que se refere aos gestos de leitura investidos na análise interpretativa da obra, Anselmo Peres Alós afirma que Puig utiliza uma estratégia que muito inquieta àqueles que se dedicam ao estudo de sua obra, a saber, as notas de rodapé. A estas e às falas em discurso direto agrega-se ainda o recurso do itálico, também utilizado por Puig, com o objetivo de marcar o monólogo interior e o pensamento introspectivo dos personagens em determinados momentos da narrativa. Desta forma, poder-se-ia pensar que um narrador "ausente" ou "obnubilado" estaria implícito, especialmente quando Molina relata filmes hollywoodianos para Valentín, tendo-se, assim, a presença de dois narradores: um narrador obnubilado, representado por Molina, e um narrador externo, representado pelo discurso articulado nas notas de rodapé. Entretanto, o autor considera improcedente a tese de que há dois narradores (ou um narrador fragmentado) e nenhuma focalização, pois, segundo Alós, a noção de focalização é mais apropriada para dar conta da heterogeneidade narrativa presente no romance do que uma suposta voz narrativa, visto que $o$ argumento que prega a autonomia dos personagens não dá conta das notas de rodapé.

Ao analisar a voz narrativa em contraste com procedimentos de focalização, no capítulo Binarismos de gênero e heteronormatividade: focalização e subversão, o autor entende que, em El beso de la mujer araña, tanto Valentín quanto Molina configuram-se como dois diferentes focalizadores, devendo-se ainda ressaltar a existência de um focalizador externo, o qual diz respeito ao focalizador que vem à tona na organização das notas de rodapé. O primeiro focalizador que merece destaque é Molina, pois sua afetação, sua "frivolidade" e sua percepção camp são as lentes por meio das quais o personagem recriará os filmes hollywoodianos que contará para Valentín, na tentativa de distraí-lo nas intermináveis horas que passam na cela. O autor analisa dois filmes contados por Molina a Valentín, visto que, através da recriação dos filmes pela oralidade, tornase possível apreender um pouco das maneiras pelas quais Molina compreende a divisão social dos gêneros. Deve-se salientar que Molina é uma personagem que reivindica para si uma identidade feminina, referindo-se a si mesmo no feminino e apaixonando-se, repetidas vezes, por homens heterossexuais, sendo esta a percepção de um homem que se coloca socialmente como mulher, ou seja, performativiza uma identidade de gênero e de orientação sexual calcada no feminino, realizando uma paródia dos regimes hegemônicos de masculinidade e feminilidade. Assim, o comportamento de Molina é tão subversivo, questionador e revolucionário no campo social das relações de gênero quanto o comportamento de Valentín o é no campo da resistência política ao regime ditatorial argentino.

O romance Onde andará Dulce Veiga?, de Caio Fernando Abreu, conta a história de um jornalista anônimo que, nos anos de 1980, decide procurar a cantora Dulce Veiga, desaparecida, misteriosamente, na década de 1960. Esse não conta com a mesma fortuna crítica que o romance de Manuel Puig. Anselmo Peres Alós salienta que uma das vertentes críticas mais fortes na interpretação de Onde andará Dulce Veiga? é a que explora as relações entre o texto e os primeiros impactos sociais da epidemia de AIDS, que atingiu escalas planetárias no final do século $X X$. No que se refere ao subtítulo de Onde andará Dulce Veiga? - um romance $B$, há uma certa unanimidade em considerá-lo como uma referência ao "cinema B", o cinema policial, ou o cinema noir. Uma leitura do subtítulo, tendo como referência o mercado fonográfico, sustenta a possibilidade de que, desde o seu subtítulo, o romance de Caio Fernando Abreu já anunciava a experimentação narrativa diferenciada do que poderia ser considerado o lado a do escritor, a saber: suas coletâneas de contos, especialmente o sucesso de crítica e vendas Morangos mofa- 
dos ${ }^{10}$ publicado em 1982. Este romance é conduzido por uma voz narrativa autodiegética, sinalizando a reivindicação, por parte de quem narra, de uma participação quase que "autobiográfica" na construção da narrativa, considerando-se o autobiográfico, aqui, como um qualificativo para a voz narrativa. A focalização, por sua vez, é predominantemente interna, principalmente em função da coincidência entre a percepção do narrador e a do personagem central. Apesar de ser possível perceber a desidentificação do focalizador no que se refere à homossexualidade "máscula" dos michês argentinos ou à feminilidade transexual da personagem Jacyr(a), ele não percebe, em nenhum momento, esses modos de se vivenciar a homossexualidade masculina como abjetos. As cristalizadas identidades de gênero são desestabilizadas pela performance de Jacyr(a), como concebidas pelo protagonista, uma vez que Jacyr(a) se apresenta ora como homem, ora como mulher.

Neste romance de Caio Fernando Abreu, considerando-se que o protagonista cumpre além do papel de narrador, o de focalizador dominante, os valores por ele articulados são identificados a partir de oposições (ou concordâncias) entre suas próprias crenças e aquelas sustentadas por outros personagens, tais como Rafic, Alberto Veiga e Márcia Felácio, permitindo, assim, apreender o lugar a partir de onde o focalizador articula seus valores e crenças.

Em No se lo digas a nadie, o autor peruano relata a história de Joaquín Camino, filho da alta burguesia peruana, desde a descoberta de sua sexualidade, ainda na infância, até a idade adulta, quando da completa constituição de uma identidade homossexual. Diferentemente de Manuel Puig e de Caio Fernando Abreu, Jaime Bayly mantém uma estreita relação com o mundo midiático e com os meios de comunicação. Bayly foi, entre os romancistas discutidos por Anselmo Peres Alós em seu livro, o que teve menos pudores ao assumir o impacto de sua biografia pessoal em seus escritos, de forma que, muitas vezes, os limites entre a ficção e a realidade foram confundidos em seus romances. Em No se lo digas a nadie, a homossexualidade "bem-comportada" (branca, masculina e de classe média) não é a única identidade cultural colocada à prova: o autor peruano também é condenado por utilizar, em seus romances, fartos diálogos e uma linguagem muito próxima da oralidade.

Na referida obra, Bayly utiliza a presumida impessoalidade de uma narrativa heterodiegética, na qual os eventos são articulados por uma voz supostamente impessoal. No se lo digas a nadie é uma obra que desmantela mitos sociais relacionados à sociedade peruana, residindo aí sua força crítica. O uso de uma linguagem coloquial e de diálogos que apontam para o fato de que é no cotidiano das microrrelações sociais que se instaura o violento confronto entre sexualidades hegemônicas e subalternizadas, tendo-se como exemplo o espancamento de uma travesti por Joaquín e seus amigos.

Em No se lo digas a nadie, Bayly articula um narrador extradiegético que, apenas no final do romance, se mostrará "acumpliciado" com a perspectiva de Joaquín Camino. Entretanto, ao longo da narrativa, é possível observar uma sintonia entre o narrador extradiegético e o personagem Joaquín Camino através da maneira como são apresentados os outros personagens, bem como suas crenças e valores. No romance de Bayly, fica evidente o alinhamento de diferentes posturas fóbicas e discriminatórias na tentativa de manutenção dos privilégios sociais de uma pequena parcela da população, desta forma, em nome da "verdadeira cidadania peruana" e do "progresso da nação", usurpa-se das mulheres, dos indígenas, dos homossexuais e das classes economicamente mais desfavorecidas, o direito de participação políitica plena no imaginário nacional.

Por fim, observa-se que as três obras analisadas a partir de um viés comparatista em $A$ letra, o corpo e o desejo têm um caráter de denúncia e questionamento; os três autores não estão apenas preocupados em delatar a violência homofóbica nas nações latino-americanas, mas também contestam o enquadramento em um modelo prêt-à-porter de identidade homossexual masculina, como acontece em Onde andará Dulce Veiga?, de Caio Fernando Abreu; questionam e subvertem o modelo heteronormativo de sexualidade e desafiam as estruturas sociais que consideram o sistema hierárquico de gênero como um binarismo restrito ao determinismo biológico, como acontece em El beso de la mujer araña, de Manuel Puig, e também questionam o tratamento dado às mulheres, indígenas, homossexuais e pessoas de classes economicamente mais desfavorecidas no que diz respeito à participação política plena no imaginário nacional, como é o caso de No se lo digas a nadie, de Jaime Bayly.

Ao final de A letra, o corpo e o desejo, o autor destaca que seu projeto, além de estético, é ético. E realmente o é, visto que dá destaque a obras da literatura latino-americana que assumem um caráter de intervenção, construindo novos sentidos para as práticas sexuais social- 
mente relegadas ao plano da abjeção. Ao apresentar uma comparação entre obras de autores que dão voz a sujeitos historicamente silenciados, o livro reitera o papel da literatura enquanto ato político, uma vez que se apresenta como importante reflexão acerca da hetenormatividade a que os sujeitos estão subordinados na sociedade latino-americana, permitindo uma crítica às formas de regulação e normativização dos sujeitos subalternizados nas sociedades patriarcais. Desta forma, o livro se apresenta como uma importante contribuição aos estudos literários e aos estudos culturais, uma vez que identifica as relações de poder da estrutura cultural presentes na heterossexualidade compulsória, evidenciando um importante contraponto a diversas formas de dominação dos sujeitos, buscando, assim, a preservação e o respeito pelas diferenças.

\section{Notas}

${ }^{1}$ ALÓs, Anselmo Peres. "A autoria feminina e a literatura brasileira no século XIX: novas perspectivas sobre a literatura indianista e a representação do embate colonial". In: BRASIL. Secretaria Especial de Políticas para as Mulheres. $1^{\circ}$ Prêmio Construindo a Igualdade de Gênero. Brasília: Secretaria Especial de Políticas para as Mulheres, 2006. p. 118-143. ${ }^{2}$ Conferir também: ALÓs, 2012a; 2012b; 2011 a; 2011 b; 2011 c; 2010; 2009a; 2009b; 2008; 2006a e 2006b.

${ }^{3}$ PUIG, Manuel. El beso de la mujer araña. Barcelona: Seix Barral, 1976.

${ }^{4}$ ABREU, Caio Fernando. Onde andará Dulce Veiga? São Paulo: Companhia das Letras, 1990.

${ }^{5}$ Embora Caio Fernando Abreu seja mais conhecido como contista, o autor escreveu também peças de teatro e romances. Além do romance Onde andará Dulce Veiga? é de sua autoria também o romance Limite branco (Rio de Janeiro: Expressão e Cultura, 1970).

${ }^{6}$ BAYLY, Jaime. No se lo digas a nadie. Barcelona: Planeta, 1994.

${ }^{7}$ Sônia Weidner MALUF, 2013.

${ }^{8}$ Anselmo Peres ALÓS, 2009C.

${ }^{9}$ ALÓS, 2009.

${ }^{10}$ ABREU, Caio Fernando. Morangos mofados. São Paulo: Brasiliense, 1982.

\section{Referências}

ABREU, Caio Fernando. Onde andará Dulce Veiga? São Paulo: Companhia das Letras, 1990

ALÓS, Anselmo Peres. A letra, o corpo e o desejo: masculinidades subversivas no romance latino-americano. Florianópolis: Mulheres, 2013.

"A literatura comparada neste início de milênio: tendências e perspectivas". Ângulo, Lorena, ano 35, n. 130, p. 7-12, jul.-set. 2012a. Disponível em: <http://www.academia.edu/ 2332236/O_morro_dos_ventos_uivantes_e_ Coracoes_migrantes_releituras_de_arquivos_ coloniais e poscoloniais $>$. Acesso em: 23 out. 2013.

ALÓS, Anselmo Peres; ALÓS, Iva Peres. "Dos direitos humanos ao direito constitucional: a questão das uniões homoafetivas". Bagoas: revista de estudos gays, Natal, v. 5, n. 6, p. 157-179, 2011 c. Disponível em: <http://www.cchla.ufrn. br/bagoas/v05n06art07_alosalos.pdf $>$. Acesso em: 20 out. 2013

"Heterotopias hipertextuais: escrevendo mundos digitais em La ansiedad e keres kojer = guan tu fak". Ipotesi, Juiz de Fora, v. 14, n. 1 p. 69-80, jan.-jul. 2010. Disponível em: <http:/ /www.ufjf.br/revistaipotesi/files/2009/10/ hetetopias-hipertextuais.pdf $>$. Acesso em: 19 ago. 2013.

ALÓS, Anselmo Peres. "Gênero, epistemologia e performatividade: estratégias pedagógicas de subversão". Estudos Feministas, Florianópolis, v. 19, n. 2, p. 421-449, 201 la. Disponível em: <http://www.scielo.br/scielo.php?pid=SO 104-026X2011000200007\&script=sci_arttext > Acesso em: 23 out. 2013.

"Literatura comparada ontem e hoje: campo epistemológico de ansiedades e incertezas". Organon, Porto Alegre, v. 27, n. 52, p. 17-42, 2012 b. Disponível em: <http://seer.ufrgs.br/organon/article/ view/33469/21342>. Acesso em: $1^{\circ}$ out. 2013.

"Prolegomena queer: gênero e sexualidade nos estudos literários". Cadernos de Letras da UFF, Niterói, n. 42, p. 199-217, 201 1b. Disponível em: <http://www.uff.br/cadernosdeletrasuff/42/ artigol 1 >. Acesso em: 15 out. 2013.

ALÓs, Anselmo Peres; SCHMIDT, Rita Terezinha. "A autoria feminina e a literatura brasileira no século XIX: novas perspectivas sobre a literatura indianista e a representação do embate colonial". In: BRASIL. Secretaria Especial de Políticas para as Mulheres. 10 Prêmio Construindo a Igualdade de Gênero. Brasília: Secretaria Especial de Políticas para as Mulheres, 2006a. p. 118-143.

"Corpo e gênero no romance oitocentista brasileiro: uma leitura de Bom-Crioulo, de Adolfo Caminha". Terra roxa e outras terras Revista de Estudos Literários, Londrina, v. 15, p. 16-25, jun. 2009b. Disponível em: <http:// www.uel.br/pos/letras/terraroxa/g_pdf/vol18/ TRvol18b.pdf $>$. Acesso em: $1^{\circ}$ out. 2013.

"Madame Satã e a encenação do feminino: impasses de um malandro travestido de vermelho". Gênero, Niterói, v. 8, n. 2, p. 369385, $1^{\circ}$ sem. 2008. Disponível em: <http:// www.revistagenero.uff.br/index.php/ revistagenero/article/view/190/128>. Acesso em: 22 out. 2013. 
"Margens da poética/poéticas da margem: o comparatismo planetário como prática de resistência". Organon, Porto Alegre, v. 23, n. 47, p. 129-145, 2009c. Disponível em <http://seer.ufrgs.br/organon/article/view/ 29514/18199 >. Acesso em: $1^{\circ}$ out. 2013.

"Texto literário, texto cultural, intertextualidade". Revista Virtual de Estudos da Linguagem, Porto Alegre, ano 4, v. 6, p. 1-25, 2006b. Disponível em: <http://www.revel.inf.br/ files/artigos/revel_6_texto_literario.pdf $>$. Acesso em: 22 out. 2013 .

. "Um exercício comparatista da leitura queer: reflexões em torno d'El beso de la mujer araña, de Manuel Puig". Crítica Cultural, Palhoça, v. 4, n. 2, p. 65-80, 2009a. Dispo- nível em: < http://www.portaldeperiodicos.uni sul.br/index.php/Critica_Cultural/article/view/ 135/147>. Acesso em: 15 ago. 2013

BAYLY, Jaime. No se lo digas a nadie. Barcelona: Planeta, 1994.

MALUF, Sônia Weidner. "Apresentação: as políticas sexuais do romance e da nação". In: ALÓS Anselmo Peres. A letra, o corpo e o desejo: masculinidades subversivas no romance latino-americano. Florianópolis: Mulheres, 2013. p. 15-24.

PUIG, Manuel. El beso de la mujer araña. Barcelona: Seix Barral, 1976.

Bárbara Loureiro Andreta Universidade Federal de Santa Maria 